\title{
Bead aggregation assay to demonstrate presynaptic differentiation induced by the NGL family of cell adhesion molecules
}

Seho Kim

KAIST

Eunjoon Kim

KAIST

\section{Method Article}

Keywords: cell adhesion, neuroligin, NGL, presynaptic differentiation, immunostaining, VGlut1

Posted Date: September 26th, 2006

DOI: https://doi.org/10.1038/nprot.2006.292

License: (c) (1) This work is licensed under a Creative Commons Attribution 4.0 International License.

Read Full License 


\section{Abstract}

\section{Introduction}

The synaptic cell adhesion molecule neuroligin bound to beads has been shown to induce the clustering of neurxin and synaptic vesicle proteins in contacting axons $\backslash[1]$. In addition, neurexin-coated beads induced clustering of neuroligin and postsynaptic proteins in contacting dendrites $\backslash[2]$. We employed this assay to demonstrate that the extracellular domain of NGL, a family of cell adhesion molecules that associates with the netrin-G family of cell adhesion molecules and the postsynaptic scaffolding protein PSD-95, bound to beads induces presynaptic differentiation in contacting axons of cultured neurons. Presynaptic differentiation was visualized by immunostaining for the presynaptic vesicle protein synaptophysin and vesicular glutamate transporter $1 \backslash$ (VGlut1; a marker for excitatory presynapses). In addition, functional presynaptic differentiation was demonstrated by vesicle turnover experiments, which monitor the uptake of synaptotagmin luminal domain antibodies $\backslash[3]$.

\section{Procedure}

**Preparation of NGL-2 ectodomain fusion proteins** 1. Transfect HEK293T cells with NGL-2-Ecto-Fc, in which the ectodomain of NGL-2 was fused to the human immunoglobulin Fc domain. 2. After 2 days of incubation, change the medium to serum-free medium and incubate for a further 3 days. 3. Purify NGL-2Ecto-Fc from the serum-free medium using protein-A sepharose. **Bead coating ${ }^{\star \star} 4$. Mix $5 \mu \mathrm{g}$ of NGL-2Ecto-Fc, $5 \mu \mathrm{g}$ of biotin-conjugated anti-human antibodies, and $2 \mu \mathrm{L}$ of neutravidin-conjugated FluoSphere beads $\backslash$ (Molecular Probes; $1 \mu \mathrm{m}$ diameter), and incubate for $1 \mathrm{~h}$. 5 . Increase the volume of the mixture to $1 \mathrm{~mL}$ by adding Hank's balanced salt solution $\backslash($ HBSS ), and centrifuge at 13,000 rpm for $1 \mathrm{~min}$ in a microcentrifuge. 6. Carefully remove the supernatant, and resuspend the precipitates in $100 \mu \mathrm{L}$ of conditioned media where neurons were growing. ${ }^{* *}$ Bead binding to neurons ${ }^{\star \star} 7$. Place the coverslips with cultured neurons \(DIV12) face-up on 6-well \(or larger) dishes. Save the conditioned media for Step 9. 8. Add $100 \mu \mathrm{L}$ of the resuspended beads onto the neurons and incubate at $37^{\circ} \mathrm{C}$ for $30 \mathrm{~min}$. Do not let the coverslips dry during bead loading. 9. Wash the neurons twice with HBSS, and place the coverslip back into the conditioned media and incubate for $24 \mathrm{~h}$. 10. Fix and immunostain the neurons with primary antibodies against various synaptic proteins and fluorophore-conjugated secondary antibodies. ${ }^{*}$ Image acquisition and quantitation $* \star 11$. Capture Z-stacked images by confocal immunofluorescence microscopy as well as DIC imaging. 12. For quantitation, manually trace the boundaries of the beads. Copy a bead boundary to a nearby axonal region for normalization. 13. The mean immunofluorescence intensity of a synaptic marker in a bead area was determined and normalized by that from a nearby control area.

\section{References}

1. Dean, C. _et al._Neurexin mediates the assembly of presynaptic terminals. _Nat Neurosci_ $* \star 6 * \star, 708-$ $16 \backslash(2003)$. 2. Graf, E. R., Zhang, X., Jin, S. X., Linhoff, M. W. \& Craig, A. M. Neurexins induce 
differentiation of GABA and glutamate postsynaptic specializations via neuroligins. _Cell_ **119**, 1013$26 \backslash(2004)$. 3. Kraszewski, K._et al._Synaptic vesicle dynamics in living cultured hippocampal neurons visualized with CY3-conjugated antibodies directed against the lumenal domain of synaptotagmin. _J Neurosci_ $* * 15^{\star \star}, 4328-42 \backslash(1995)$. 